BMJ Open

Diabetes

Research

\& Care

\title{
Baseline hemoglobin A1c and risk of statin-induced diabetes: results of Veterans Affairs Database analysis
}

\author{
Anna P Ziganshina (D) , ${ }^{1}$ Darren E Gemoets, ${ }^{2}$ Laurence S Kaminsky, ${ }^{2}$ \\ Aidar R Gosmanov (D) ${ }^{1,3}$
}

To cite: Ziganshina AP, Gemoets DE, Kaminsky LS, et al. Baseline hemoglobin A1c and risk of statininduced diabetes: results of Veterans Affairs Database analysis. BMJ Open Diab Res Care 2022;10:e002554. doi:10.1136/ bmjdrc-2021-002554

LSK since deceased.

Received 17 August 2021 Accepted 7 December 2021

D) Check for updates

(C) Author(s) (or their employer(s)) 2022. Re-use permitted under CC BY-NC. No commercial re-use. See rights and permissions. Published by BMJ.

${ }^{1}$ Division of Endocrinology, Albany Medical College, Albany, New York, USA

${ }^{2}$ Research and Development, Stratton VA Medical Center, Albany, New York, USA ${ }^{3}$ Endocrinology Section, Stratton VA Medical Center, Albany, New York, USA

Correspondence to Dr Aidar R Gosmanov; agosmanov@gmail.com
Development of new-onset diabetes mellitus (NODM) is one of the side effects of statin therapy. ${ }^{1}$ Since the absolute risk of statininduced diabetes is small, it remains unclear if there are any specific factors that might predispose to hyperglycemia following statin initiation. Conditions such as metabolic syndrome, hypertension, and/or low exercise tolerance $^{2}$ have been proposed as potential risk factors based on relatively small prospective trials or observational studies that were not initially designed for evaluating of statininduced NODM. The goal of this study was to determine if baseline level of hemoglobin A1c (HbAlc) is a significant and independent risk factor that increases the risk of statin-induced diabetes.

This was a retrospective nationwide cohort study of US Veterans without prior diagnosis of diabetes started on most commonly used in Veterans Healthcare Administration system statins (atorvastatin, simvastatin, pravastatin). Between January 2011 and December 2018, we identified 152358 patients using the following inclusion criteria: availability of full demographic and clinical information, baseline $\mathrm{HbA} 1 \mathrm{c}<6.5 \%$, no International Classification of Diseases, Ninth Version (ICD-9) diagnosis of diabetes or use of diabetes medications except metformin (as it can be used in the management of pre-diabetes), baseline calculated low-density lipoprotein cholesterol (LDL-C) value, and adequate adherence to statins (determined based on proportion of days covered $\geq 80 \%)^{3}$ (table 1). Baseline HbAlc values were stratified into three categories: $\leq 5.6 \%, 5.7 \%-5.9 \%$ and $6.0 \%-6.4 \%$. The risk of statin-induced NODM was assessed in the whole cohort and according to the above baseline HbA1c categories using Cox proportional hazards model adjusted for case-mix. Covariates for risk adjustment included: age, gender, ethnicity, obesity, hypertension, coronary artery disease, baseline LDL-C level, cerebrovascular disease, and metformin use. Effect size measures of omega squared for continuous variables and Cramer's V for categorical variables quantified degree of possible confounding.

Mean study follow-up was 6.89 (SD 2.26) years in non-statin users and 3.85 (SD 2.29) years in statin users. The rate of statin-induced NODM was similar to prior observations $(1,2)$, with an estimate of 224.5 additional cases of diabetes per 10000 patients during 4-year study period compared with non-users. We found that in the adjusted models, statininduced NODM risk was inversely related to baseline HbAlc (table 1). In overall statin users' group, HRs were 2.08 (1.85 to $2.35), 1.57$ (1.40 to 1.75$)$ and 1.03 (0.93 to $1.15)$ for HbAlc groups of $\leq 5.6 \%, 5.7 \%$ $5.9 \%$ and $6.0 \%-6.4 \%$, respectively $(\mathrm{p}<0.0001$ for decreasing trend in HRs). This trend persisted when either atorvastatin, simvastatin and pravastatin were analyzed individually or all statins were grouped based on the LDL-C-lowering potency (table 1). There was no significant difference in diabetogenic risk among different statin groups. The body mass index changes in the statin users throughout the observation period did not alter their diabetogenic risks regardless of A1c category (data not shown).

The results of this largest to date analysis of the diabetogenic risk in statin and nonstatin users closely matched for baseline characteristics suggest that the rate of statininduced NODM may have reverse association with baseline HbAlc. We hypothesize that our findings can be explained by the fact that HbAlc between $6.0 \%$ and $6.4 \%$ is by itself associated with high diabetes development risk and thus additional risks from statin therapy are no longer significant. In one systematic review, Zhang et al showed that 


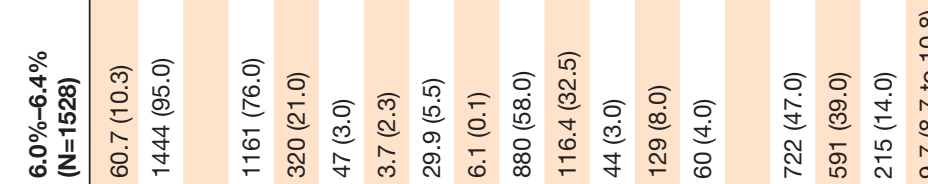

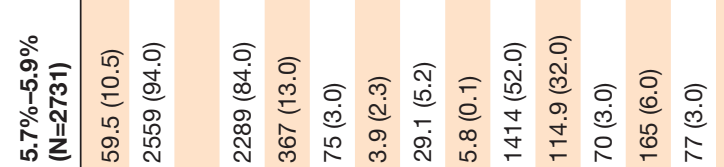

$\stackrel{\infty}{\Phi}$

苟

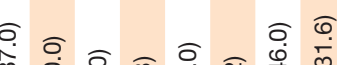

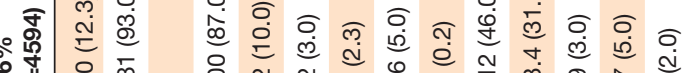

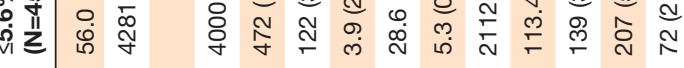

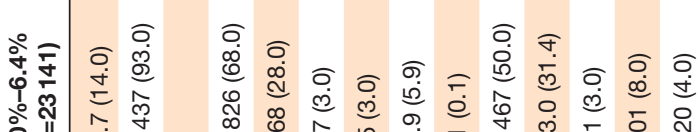

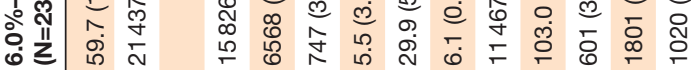

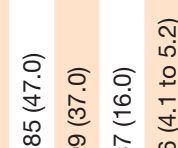

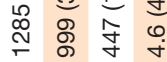

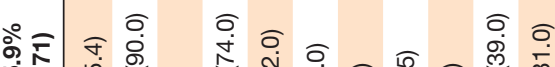

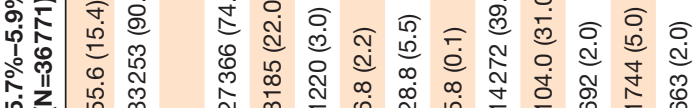

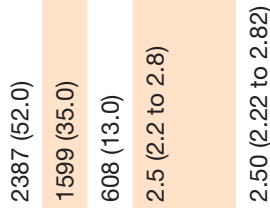

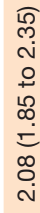

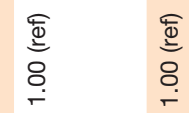

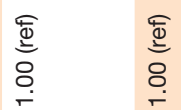

$\stackrel{\overline{\mathrm{Q}}}{\stackrel{8}{\circ}}$

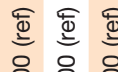

$\stackrel{+}{\circ} \stackrel{i}{\circ} \stackrel{8}{\circ}$

ब्ब

움

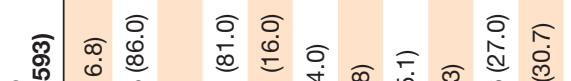

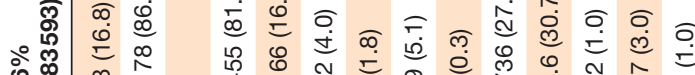

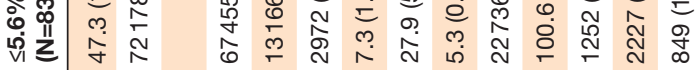

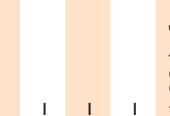

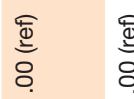

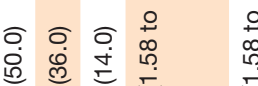

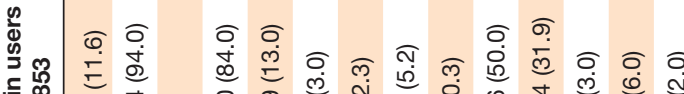

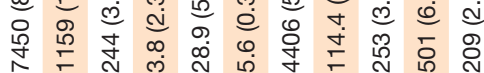

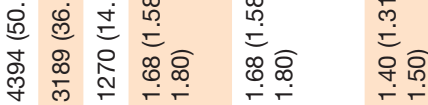

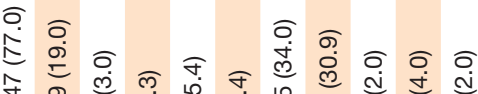

粮

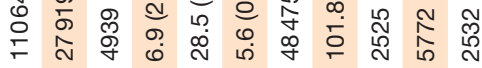

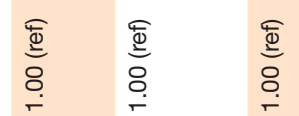

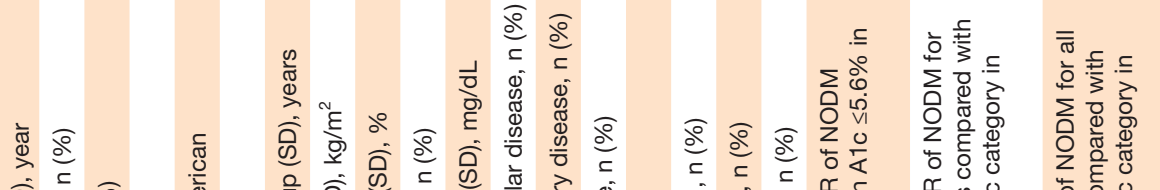

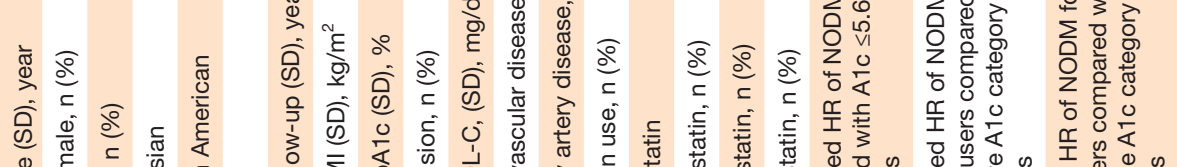

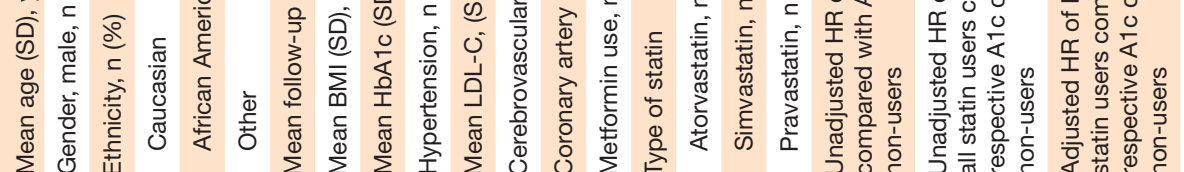

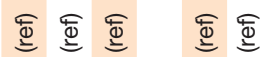
움 움 
the highest risk of developing type 2 diabetes is in the individuals with $\mathrm{HbA1c} \geq 6.0 \%$. Among statin non-users with baseline HbAlc 6.0\%-6.4\%, unadjusted HR for NODM was 9.3, consistent with findings in the systematic review by Zhang et al; of note, this risk was not significantly different from the risk of NODM in the statin users (table 1). Our hypothesis is supported by the findings from the trials where higher incidence of statin-induced NODM was reported in subjects with mean baseline HbA1c $<6.0 \%{ }^{5}$ and the studies that demonstrated lower incidence of NODM when baseline dysglycemia was more pronounced. ${ }^{6}$

Our study has limitations. It was a retrospective analysis conducted in the government-funded healthcare system and majority of the patients were white and male. The strengths are that we tried to match all subjects as close as possible and included only patients who adhered to the statin treatment. The results of this retrospective observational trial with DM risk as the primary outcome can be particularly clinically relevant because older patients with pre-diabetes may have high cardiovascular (CV) risk and are often candidates for statin therapy. Providers and patients may perceive the risk of statin-induced diabetes as a negative factor in decision to initiate statin therapy. Our results suggest that individuals with $\mathrm{HbAlc}$ between $6.0 \%$ and $6.4 \%$ who may have significant baseline CV risk may in fact not be at higher risk of developing diabetes which should alleviate concerns of new-onset dysglycemia from statin use in clinical practice. We also suggest that the A1c value at the time of a patient-provider shared decision-making session should be included to discuss diabetogenic risks of statin therapy.

Acknowledgements This material is the result of work supported with resources and the use of facilities at the Stratton VAMC, Albany, New York, USA.

Contributors APZ researched data and wrote the manuscript. DEG analyzed data and contributed to the discussion. LSK contributed to the discussion. ARG contributed to the study design, cohort development, data interpretation and reviewed/edited the manuscript. All authors participated in drafting the article and revising it critically for important intellectual content. All authors provided their approval of this version of the manuscript for publication. ARG is the guarantor of this work and, as such, had full access to all the data in the study and takes responsibility for the integrity of the data and the accuracy of the data analysis.

Funding The authors have not declared a specific grant for this research from any funding agency in the public, commercial or not-for-profit sectors.

Disclaimer The opinions expressed in this paper are those of the authors and do not represent the views of the Department of Veterans Affairs or the US Government.

Competing interests DEG, LSK, and ARG are employees of the US Department of Veterans Affairs. ARG serves as an Associate Editor of the BMJ Open Diabetes Research \& Care and Journal of Clinical and Translational Endocrinology. The other authors declare no competing interests.

Patient consent for publication Not required.

Ethics approval The study was approved by the Stratton Veterans Affairs Medical Center Institutional Review Board, Albany, New York, USA.

Provenance and peer review Not commissioned; externally peer reviewed.

Open access This is an open access article distributed in accordance with the Creative Commons Attribution Non Commercial (CC BY-NC 4.0) license, which permits others to distribute, remix, adapt, build upon this work non-commercially, and license their derivative works on different terms, provided the original work is 
properly cited, appropriate credit is given, any changes made indicated, and the use is non-commercial. See: http://creativecommons.org/licenses/by-nc/4.0/.

\section{ORCID iDs}

Anna P Ziganshina http://orcid.org/0000-0001-8220-9251

Aidar R Gosmanov http://orcid.org/0000-0002-4197-5344

\section{REFERENCES}

1 Rajpathak SN, Kumbhani DJ, Crandall J, et al. Statin therapy and risk of developing type 2 diabetes: a meta-analysis. Diabetes Care 2009;32:1924-9.

2 Betteridge DJ, Carmena R. The diabetogenic action of statins - mechanisms and clinical implications. Nat Rev Endocrinol 2016;12:99-110.
3 Canfield SL, Zuckerman A, Anguiano RH, et al. Navigating the wild West of medication adherence reporting in specialty pharmacy. $J$ Manag Care Spec Pharm 2019;25:1073-7.

4 Zhang X, Gregg EW, Williamson DF, et al. A1C level and future risk of diabetes: a systematic review. Diabetes Care 2010;33:1665-73.

5 Ridker PM, Danielson E, Fonseca FAH, et al. Rosuvastatin to prevent vascular events in men and women with elevated C-reactive protein. N Engl J Med 2008;359:2195-207.

6 Sever PS, Dahlöf B, Poulter NR, et al. Prevention of coronary and stroke events with atorvastatin in hypertensive patients who have average or lower-than-average cholesterol concentrations, in the Anglo-Scandinavian Cardiac Outcomes Trial-Lipid Lowering Arm (ASCOT-LLA): a multicentre randomised controlled trial. Lancet 2003;361:1149-58. 